\title{
Congenital duplication of mastoid segment of facial nerve: A rare case report
}

\author{
Ravi Kanth Jakkani, Ragavendra KI, Aruna Karnawat, Vittal R, Anjani D Kumar \\ Department of Radiology, Consultant Radiologist, Yashoda Hospital, Secunderabad, Andhra Pradesh, India \\ Correspondence: Dr. Ravi Kanth Jakkani, Consultant Radiologist, Yashoda Hospital, Secunderabad, Andhra Pradesh, India. \\ E-mail: ravikanthjakkani@gmail.com
}

\begin{abstract}
Congenital duplication of facial nerve is a very rare anomaly commonly associated with inner and middle ear anomalies. There can be duplication of mastoid, tympanic, or labyrinthine segments. We describe duplication of mastoid segment of facial nerve in a young female who also showed middle ear anomalies and external auditory canal atresia.
\end{abstract}

Key words: Chorda tympani nerve; computed tomography; facial nerve; stylomastoid foramen

\section{Introduction}

Duplication of facial nerve is a very rare anomaly commonly associated with middle and inner ear anomalies. It can involve any segment of intratemporal facial nerve. It is important look for this anomaly in all patients with congenital deafness and ear anomalies. Knowledgeof this anomaly is useful in presurgical evaluation to avoid inadvertent nerve injury and also in recognizing associated middle and inner ear anomalies.

\section{Case Report}

A 15-year-old female presented to the ENT department at our hospital with history of progressive hearing loss detected at school age. There was no history of either pus discharge or ear pain. Also, there was no history of any congenital infection, trauma, or any surgery. Clinical examination showed well-formed pinna with atresia of external auditory canal. There was conductive type of

\begin{tabular}{|l|l|}
\hline \multicolumn{2}{|c|}{ Access this article online } \\
\hline Quick Response Code: & \\
\cline { 1 - 2 } & Website: \\
\hline & www.ijri.org \\
\cline { 2 - 3 } & DOI: \\
\hline ⿴囗口 & 10.4103/0971-3026.113618 \\
\hline
\end{tabular}

hearing loss. No facial nerve abnormalities were detected. Audiometry study showed low-frequency hearing loss in the right ear up to $60 \mathrm{~dB}$. Patient underwent high-resolution computed tomography (HRCT) of temporal bone in our department.

HRCT temporal bone showed atresia of the right external auditory canal. Middle ear ossicles were dysplastic with hypoplastic malleus which was fused with deformed incus [Figure 1]. Stapes was absent. The inner structures, cochlea, vestibule, and semicircular canals, were unremarkable. We traced the course of facial nerve and found duplication of mastoid segment of facial nerve with two stylomastoid foramina on the right side [Figure 2]. Mastoid segment of the facial nerve divides into lateral and medial segments with larger lateral segment branch which carries enlarged chorda tympani branch and medial segment branch continues as tympanic branch of the facial nerve [Figure 3]. There was no duplication of tympanic and labyrinthine segments of the facial nerve [Figure 4].

\section{Discussion}

Facial nerve anomalies are commonly associated with ossicular chain anomalies. This is explained by the fact that ossicular structures develop from the first and second branchial arches and facial nerve develops from the second arch. ${ }^{[1,2]}$ Congenital dehiscence of tympanic segment of facial nerve is the most commonly seen anomaly of the facial 

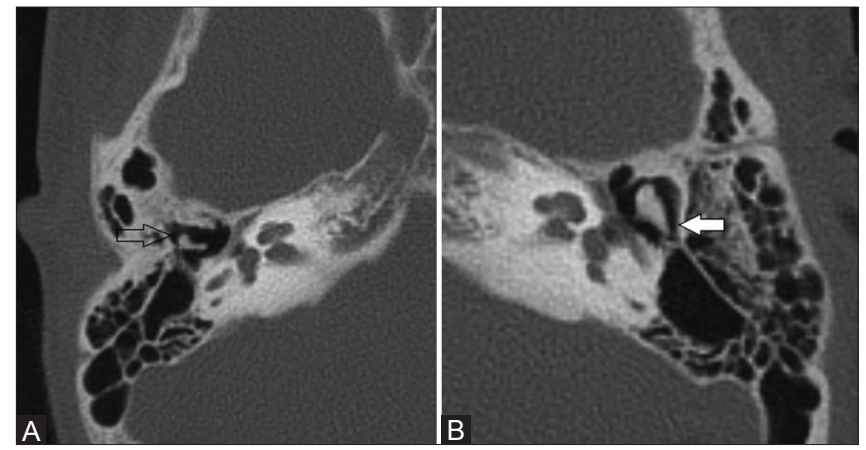

Figure 1 (A, B): (A) Right and (B) left axial CT sections through temporal bones show hypoplastic and deformed malleus and incus which are fused to each other on the right side (open arrow) and normal ossicles on the contralateral side (white solid arrow)

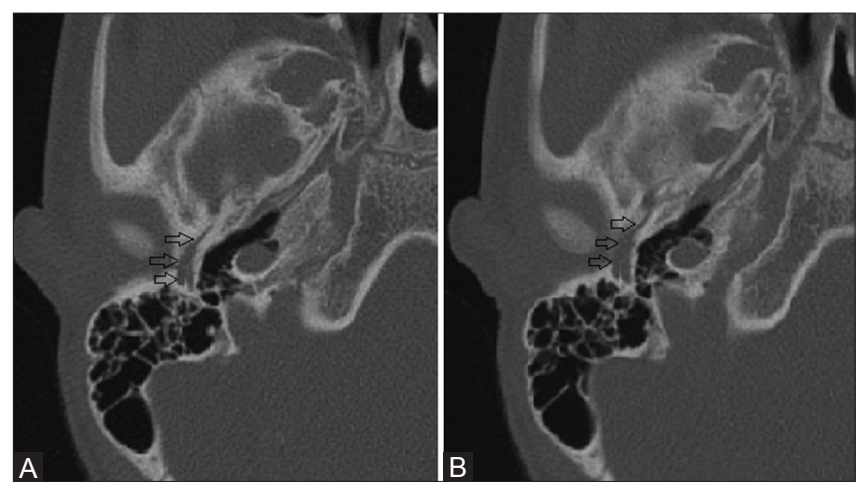

Figure 3 (A, B): (A and B) Serial axial CT sections of the temporal bone show bifurcation of mastoid segment of the facial nerve into medial and lateral segments; the lateral segment carries enlarged chorda tympani branch (open arrows) and the medial segment carries rest of the tympanic segment of the facial nerve

nerve. ${ }^{[3]}$ Duplication of facial nerve is a very rare anomaly associated with middle and inner ear anomalies. Bifurcation of mastoid, tympanic, labyrinthine, and canalicular segments of facial nerve has been variously described in the literature. ${ }^{[4]}$ Bifurcation of tympanic segment is most frequently reported and can be associated with congenital stapes fixation and oval window atresia. ${ }^{[5]}$ Labyrinthine segment division is an extremely rare occurrence with a single case report in the literature. ${ }^{[4]}$ There are few isolated case reports describing bifurcation of mastoid segment of the facial nerve. ${ }^{[6,7]}$ In patients with external auditory canal atresia, often the facial nerve shows altered course with mastoid segment passing along or through the atretic bone plate resulting in increased risk of injury during surgical repair. ${ }^{[8]}$ Other variations in facial nerve course in this anomaly include anteriolateral displacement of stylomastoid foramen with extracranial course of facial nerve making it vulnerable for injury during surgery. Tympanic segment of facial nerve may be caudally displaced and overlying the oval window putting it at risk for injury during surgery. ${ }^{[8,9]}$

HRCT of temporal bone accurately depicts the facial nerve anatomy and its anomalies. Bifurcation of mastoid
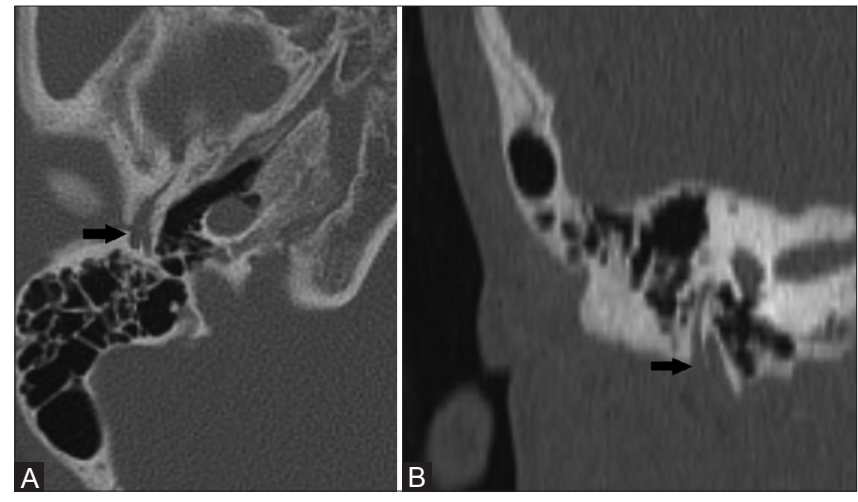

Figure 2 (A, B): (A) Axial and (B) coronal reconstructed CT sections through temporal bones show two stylomastoid foramenith duplication of mastoid segment of the facial nerve (solid black arrow)

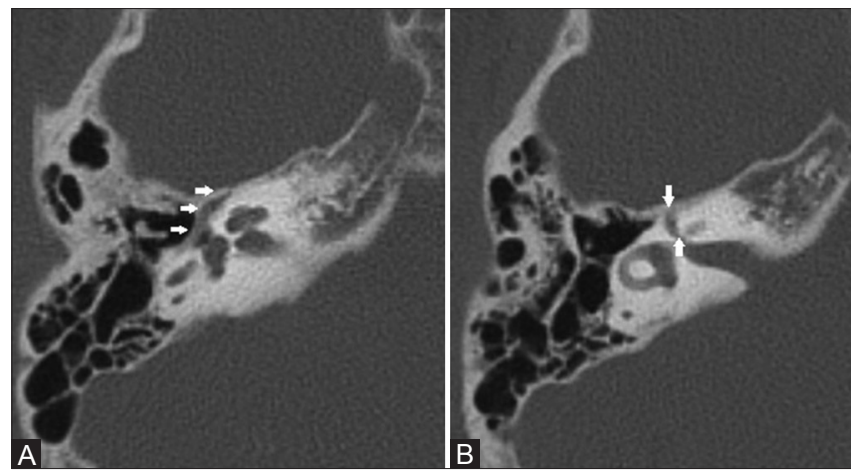

Figure 4 (A, B): (A and B) Axial CT sections of temporal bone show normal tympanic and labyrinthine segments of the facial nerve

segment is shown on $\mathrm{CT}$ as division of facial nerve at the level of stylomastoid foramen with symmetric bifid facial nerve segments coursing in two stylomastoid foramina. The lateral foramen contains the enlarged chorda tympani branch and courses in close relation to mastoid bone. ${ }^{[6,10]}$ It is important to recognize this anomaly as there is risk of nerve injury during mastoidectomy or cochlear implant placement. ${ }^{[11]}$ Bifurcation of tympanic segment of the facial nerve usually occurs adjacent to oval window, with reunion of bifid segments distal to stapes or at posterior genu. Bifid segment of the facial nerve courses over oval window with increased risk of injury during stapedectomy, and hence it is important to recognize this anomaly. ${ }^{[10]}$ Division of labyrinthine segment of the facial nerve is extremely rare and is associated with cochlear and vestibular anomalies. ${ }^{[4]}$ Bifurcation of intracanalicular part of the facial nerve with separate or no bony septa has been described..$^{[12]}$

\section{Conclusion}

Facial nerve duplication is a rare anomaly often associated with middle and inner ear anomalies. It is important for the radiologist to be aware of this entity and carefully look for this anomaly while reviewing $\mathrm{CT}$ of temporal bone. Major presurgical implication of this anomaly can avoid 
inadvertent injury to the facial nerve during surgery. Also, recognizing this anomaly should alert the radiologist to look for other anomalies.

\section{References}

1. Jahrsdoerfer RA, Gillenwater AM. The facial nerve in congenital ear malformations. Eur Arch Otorhinolaryngol 1994:S299-301.

2. Jahrsdoerfer RA. Embryology of the facial nerve. Am J Otol 1988;9:423-36.

3. Di Martino E, Sellhaus B, Haensel J, Schlegel JG, Westhofen M, Prescher A. Fallopian canal dehiscences: A survey of clinical and anatomical findings. Eur Arch Otorhinolaryngol 2005; 262:120-6.

4. Glastonbury CM, Fischbein NJ, Harnsberger HR, Dillon WP, Kertesz TR. Congenital bifurcation of the intratemporal facial nerve. AJNR Am J Neuroradiol 2003;24:1334-7.

5. Kieff DA, Curtin HD, Healy GB, Poe DS. A duplicated tympanic facial nerve and congenital stapes fixation: An intraoperative and radiographic correlation. Am J Otolaryngol 1998;19:283-6.

6. Nager GT. Pathology of the ear and temporal bone. Philadelphia:
Lippincott Williams and Wilkins; 1993. p. 147-64.

7. Fowler EP. Variations in the temporal bone course of the facial nerve. Laryngoscope 1961;71:937-44.

8. Yeakley JW, Jahrsdoerfer RA. CT evaluation of congenital aural atresia: What the radiologist and the surgeon need to know. J Comput Assist Tomogr 1996;5:724-31.

9. Gassner EM, Mallouhi A, Jaschke WR. Preoperative evaluation of external auditory canal atresia on high-resolution CT. AJR Am J Roentgenol 2004;182:1305-12.

10. Basek M. Anomalies of the facial nerve in normal temporal bones. Ann Otol Rhinol Laryngol 1962;71:382-90.

11. Raine CH, Hussain SS, Khan S, Setia RN. Anomaly of the facial nerve and cochlear implantation. Ann Otol Rhinol Laryngol Suppl 1995;166:430-1.

12. Celin SE, Wilberger JE, Chen DA. Facial nerve bifurcation within the internal auditory canal. Otolaryngol Head Neck Surg 1991;104:389-93.

Cite this article as: Jakkani RK, Ragavendra KI, Karnawat A, Vittal R, Kumar AD. Congenital duplication of mastoid segment of facial nerve: A rare case report. Indian J Radiol Imaging 2013;23:35-7.

Source of Support: Nil, Conflict of Interest: None declared.

\section{Author Help: Reference checking facility}

The manuscript system (www.journalonweb.com) allows the authors to check and verify the accuracy and style of references. The tool checks the references with PubMed as per a predefined style. Authors are encouraged to use this facility, before submitting articles to the journal.

- The style as well as bibliographic elements should be $100 \%$ accurate, to help get the references verified from the system. Even a single spelling error or addition of issue number/month of publication will lead to an error when verifying the reference.

- Example of a correct style Sheahan P, O'leary G, Lee G, Fitzgibbon J. Cystic cervical metastases: Incidence and diagnosis using fine needle aspiration biopsy. Otolaryngol Head Neck Surg 2002;127:294-8.

- Only the references from journals indexed in PubMed will be checked.

- $\quad$ Enter each reference in new line, without a serial number.

- $\quad$ Add up to a maximum of 15 references at a time.

- If the reference is correct for its bibliographic elements and punctuations, it will be shown as CORRECT and a link to the correct article in PubMed will be given.

- If any of the bibliographic elements are missing, incorrect or extra (such as issue number), it will be shown as INCORRECT and link to possible articles in PubMed will be given. 